\title{
Regulation of Medicines Advertisement in Zimbabwe: An Assessment of The Impact of Pharmaceutical Promotion On The Prescribing Behaviour of Healthcare Professionals
}

Tafadzwa Collins Semu ( $\square$ semutc@gmail.com )

University of Zimbabwe

\section{Bernard NGARA}

University of Zimbabwe

Tinashe Mudzviti

University of Zimbabwe

\section{Research Article}

Keywords: Pharmaceutical promotion, Regulation, Knowledge, Attitudes, Perception, Healthcare workers

Posted Date: September 7th, 2021

DOl: https://doi.org/10.21203/rs.3.rs-863116/v1

License: (c) (1) This work is licensed under a Creative Commons Attribution 4.0 International License.

Read Full License

Version of Record: A version of this preprint was published at BMC Health Services Research on December 1st, 2021. See the published version at https://doi.org/10.1186/s12913-021-07399-9. 


\section{Abstract}

\section{Background}

The pharmaceutical industry plays a key role in drug discovery and is considered useful regards to informing the health care workers health care workers about new medicines. There are growing concerns related to regulating promotion of pharmaceutical products and there is notable evidence to suggest it has a significant impact health care workers' decision-making. Investigations concerning health care workers to industry interactions are less common. The objective of this study is to determine levels of knowledge, attitude and perception towards regulation of pharmaceutical promotion among healthcare practitioners in Zimbabwe.

\section{Methods}

A cross-sectional study was used and 330 healthcare practitioners were enrolled into the study. Data collection was done through combined face-to-face interviews and web-based online survey. The study was approved for ethics by the Joint Research Ethics Committee. We calculated the relative importance index score and use as a measure the of knowledge, attitude and perception levels towards pharmaceutical promotion. Univariate and bivariate analysis was performed using STATA software package.

\section{Results}

Our study estimated that $95 \%, 67 \%$, and $90 \%$ of the healthcare practitioners in Zimbabwe have a favourable (i.e. $>65 \%$ ) relative importance index score of knowledge, attitudes, and perception, respectively, towards regulation of pharmaceutical promotion. Further exploration of the data indicated that the factors that had an association with the knowledge, attitude and perception levels towards regulation of pharmaceutical regulation at $5 \%$ level of significance include health care workers' profession, gender, education level, the nature of the working institution and the number of prescriptions involved per week.

\section{Conclusion}

In conclusion, the findings of this study highlighted that in general the health care workers in Zimbabwe have higher levels of knowledge, attitude and perception towards regulation of pharmaceutical promotion, though the attitudes levels was lower compared to other domains. Further studies aimed at understanding or evaluating various aspects for the regulation of pharmaceutical promotion are recommended in order to complement the findings of this study.

\section{Background}

The pharmaceutical industry is among the most important and essential sectors in the world and it continues to expand as time moves on [1]. The pharmaceutical industry plays a key role in drug discovery 
and is considered useful regards to informing health care workers (HCWs) about medicines [2, 3]. Pharmaceutical companies have shown a tendency to allocate more resources in the form of administration expenditures to the promotion of their products than they spend for drug research and development [4]. Pharmaceutical promotion is defined as information and persuasive activities by the pharmaceutical industry that has an effect to prescription, supply, or use of medicinal drugs. Globally, data shows that the average promotional expenditures for the pharmaceutical industry is estimated to be considerably high around $15-25 \%$ while for other industries is around $2 \%$ of the total revenues [5]. Different forms of services and favours are offered by the pharmaceutical industry to HCWs that include continued education, conference travel expenses, drug samples, and research grants [6]. Most of the promotional activities are usually done to establish relationships that have a significant impact on HCWs decision-making $[4,7,8]$.

HCWs have a pivotal role in provision of proper education on disease and rational therapies to the public [9]. It is generally acceptable that HCWs should be involved in distribution of medicines in a safe and effective manner [10]. HCWs end up getting involved in relationships with the pharmaceutical industries because the HCWs are well positioned to advocate for the patients by speaking through public policy making issues related to the delivery of drug therapy and health care [11].The pharmaceutical industry is complicated in that the end-user is the patient and not the HCWs, hence the main reason why the pharmaceutical industry recognize that it key to influence the regulatory and practises of HCWs [12]. There are several information resources available to the public such as medical journals and formularies, but most of the HCWs have shown that they depend largely on pharmaceutical promotion, especially in less developed or developing countries where HCWs end up taking inappropriate decisions [13-16]. A systematic review of previous studies in developing countries on the effects of promotion on healthcare practitioners' behaviour found that at least $50 \%$ of the healthcare practitioners had their choice of drug influenced by pharmaceutical promotion [17-21].

The regulation of pharmaceutical promotion is necessary in resolving the conflict between the pharmaceutical industry's business objectives and that of patients or societal expectations which is to use medicine in the most rational way [22]. However, currently there are existing challenges in regulating their efforts to increase profit especially since pharmaceutical industry is the innovation hub of medicines [23].The national and international regulations to control pharmaceutical promotional activities were initiated around the 1980s. In Zimbabwe, the Medicines Control Authority of Zimbabwe developed the regulation by adopting the World Health Assembly resolutions of 13th May 1988 on Ethical Criteria for Medicinal Drug Promotion, together with a number of policies adopted by the authority over a number of years. Currently the general requirements for pharmaceutical promotion are governed using Sect. 35 of the Medicines and Allied Substances Control (General) Regulations, 1991, SI 150 of 1991.

The inappropriate use of medication result in waste of resources, inappropriate patient demand, drug resistance, and increased drug related morbidity and mortality. Many factors contribute to the inappropriate use of medicines, including not only a lack of information but also inaccurate and misleading promotional information. A study conducted in Zimbabwe's pharmaceutical sector reported 
that less than $44 \%$ of the advertisements listed contraindications, adverse effects, major interactions, warnings and precautions and treatment for overdose, and none had complete information as stipulated by the Medicines and Allied Substances Control Act [24].

While Zimbabwe and many other less developed or developing countries have regulation on pharmaceutical promotion in place, the lack of accurate information on regarding how it affects the healthcare practitioners' behaviour among other factors, makes it difficult to assess how well pharmaceutical promotion is working. Up to date we have not come upon investigations that seek to determine the healthcare practitioners' levels of knowledge, attitude and perception (KAP) towards regulation of pharmaceutical promotion, which is the objective of this study. In addition, this study will also explore HCWs characteristics associated with the KAP levels.

\section{Method}

\section{Data source}

The study targeted medical doctors, pharmacists, nurses and, medical/paramedical students practicing in both the public and private institutions of the healthcare sector in Harare, Zimbabwe in the year 2021. A cross-sectional study was applied to enrol study participants in their individual capacity. A semistructured data collection questionnaire was developed through an extensive review of available literature on KAP of medical professionals regarding regulation of pharmaceutical promotion, and also by reviewing of questionnaires used in similar studies done before. The questionnaire was also validated by the subject experts for its content and relevance.

In addition to the data on HCWs characteristics, indicators were developed and classified into three main domains to evaluate the KAP levels towards regulation of pharmaceutical promotion separately. Each domain consisted a list of indicators collected on a 5-point Likert scale with responses ranging from strongly disagree- 1 to strongly agree- 5 . The questionnaire was pretested by piloting the tool to 30 participants, and the necessary corrections were made to the final questionnaire based on results of the pilot survey. The final questionnaire was administered face-to-face by trained interviewers and also selfadministered by the study participants using an online survey tool which was created in REDCap hosted by the University of Zimbabwe Faculty of Medicine and Health Sciences.

\section{Data management and analysis}

Relative Importance Index (RII) scores calculated for each of the three KAP domains and expressed as a percentage of the maximum possible score. The domain score $=$ (obtained score - minimum possible score)/ (maximum possible score - minimum possible score). In this study, the RIl score was further classified favourable if RII is greater or equal to $65 \%$, while less than $65 \%$ was classified as unfavourable. We used proportions to summarize qualitative data. We used mean and standard deviation or median and interquartile ranges to summarize quantitative data, where appropriate. We used chi-square test to determine association between both qualitative independent and dependent study variables. We used the 
t-test or analysis of variance to determine association between qualitative independent and quantitative dependent study variables. Participants with missing response for a particular variable were exclude from any of the analysis that involved that variable. Statistical tests were concluded at $5 \%$ level of significance. All data analysis were carried out in STATA software package.

\section{Results}

\section{Descriptive characteristics of study participants}

A total of combined 330 participants responded to both the web-based online and face-to-face survey. Of the total study participants, $30 \%$ were medical doctors, $41 \%$ were pharmacists, $11 \%$ were nurses, and $19 \%$ were medical sciences students. The mean age was 36 years. About $63 \%$ were male participants. The median working experience was 11 years. $11 \%$ were educated up to PhD level, $53 \%$ master's degree, $23 \%$ bachelor's degree. $20 \%$ were working at public institutions only, $34 \%$ private institutions only and $34 \%$ both private and public institutions. The median number of prescriptions per week for the study participants was $50.67 \%$ were above $65 \%$ of the aggregated attitude score. $95 \%$ were above $65 \%$ of the aggregated knowledge score. $90 \%$ were above $65 \%$ of the aggregated knowledge score

\section{Knowledge Levels Toward Pharmaceutical Promotion}

An estimated $69 \%$ agreed that term pharmaceutical promotion refers to marketing of a drug product. $62 \%$ are aware of the guidelines for advertising and promotion of medicines in Zimbabwe. $80 \%$ agreed that medicines in Zimbabwe cannot be advertised without the approval of the Medicines Control Authority in writing. $86 \%$ agreed that the advertisement of any unregistered medicine is not permitted. $78 \%$ agreed that a person is not permitted to advertise medicines in connection with any bonus or discount offered. $83 \%$ agreed that changes to the approved advertising material should also go through the approval process. $74 \%$ agreed that advertisements should not be directed at children. $87 \%$ agreed with the assumption that a new product efficacy, quality and safety are similar to the already available medicines. $41 \%$ agreed that the pharmacist is not allowed to dispense a different brand of the drug without referring back to the prescriber. $78 \%$ agreed that advertisements should claim that a medicine can cure, prevent, or relieve an ailment only if this can be substantiated. $92 \%$ agreed that information on adverse reactions, precautions, contraindications and warnings, food and medicine interactions should be available before advertisement. $75 \%$ agreed that advertisements to the general public should help people to make rational decisions on the use of medicines. Additional information is available in Fig. 1.

\section{Attitude levels toward pharmaceutical promotion}

$90 \%$ support initiatives towards regulation of medicines advertisement. $67 \%$ agreed that regulation manages to avoid the pharmaceutical industry from influencing healthcare workers on decisions to prescribe and dispense. $79 \%$ agree that regulation reserve rights for patients to be given enough 
explanations about the reasons for choice of medicines for them. $20 \%$ agree that regulation should not allow health care workers in Zimbabwe the right for medicine substitution. 88\% agree that regulation improves the ethical and professional behaviour, putting patients first and compliance in the presence of medicines advertisement. 51\% agree that regulation has improved the standards for interactions between companies and healthcare practitioners. $30 \%$ agree that regulation should avoid companies from sponsorship or support for healthcare practitioners' attendance at meetings and continuing medical education. $48 \%$ agree that regulation should demand acceptable venues and locations for meetings and continuing medical education. $22 \%$ agree that regulation should avoid the provision of promotional aids by pharmaceutical industries. Additional information is available in Fig. 2.

\section{Perception levels toward pharmaceutical promotion}

About $77 \%$ agreed that the intensity of promotional activities by medical representatives should be regulated. 83\% agreed that health authorities in Zimbabwe should implement policies such that bioequivalence data are mandatory before a product is marketed. About $84 \%$ agreed that poor regulation of pharmaceutical promotion may lead to sub-optimal prescription. $86 \%$ agreed that poor regulation of pharmaceutical promotion may lead to sub-optimal dispensing. $79 \%$ agreed that poor regulation of pharmaceutical promotion may lead to over-expenditure on medicines. $77 \%$ agreed that poor regulation of pharmaceutical promotion can influence unjustified medicines regimen switching. $66 \%$ agreed that poor regulation of pharmaceutical promotion allows pharmacists to perform medicine substitution without consulting the prescribing physician. Additional information is available in Fig. 3.

\section{Factors associated with knowledge towards pharmaceutical promotion}

There was an association between aggregated knowledge RII score and profession of the participant $(\mathrm{p}=$ 0.001 ), $100 \%$ of the pharmacists and nurse had a knowledge RII score above $65 \%$, while $92 \%$ and $88 \%$ of the medical sciences students and medical doctors, respectively, had a knowledge RII score above $65 \%$. There was an association between aggregated knowledge RII score and gender of the participant $(p=$ 0.008), $100 \%$ of the female participants had a knowledge Rll score above $65 \%$, while $94 \%$ of the male participants had a knowledge RII score above $65 \%$. There was an association between aggregated knowledge RII score and education level of the participant $(p=0.028), 100 \%$ of the participants educated up to $\mathrm{PhD}$ or bachelor's degree had a knowledge RII score above $65 \%$, while $94 \%$ and $87 \%$ of the participants educated to master's degree and medical sciences students, respectively, had a knowledge RII score above $65 \%$. There was an association between aggregated knowledge RII score and working institution of the participant $(p<0.001), 100 \%$ of the participants working at private only or both public and private had a knowledge RII score above $65 \%$, while $88 \%$ and $82 \%$ of the participants working as students or public sector only, respectively, had a knowledge RII score above $65 \%$. There was no association between aggregated knowledge RII score and age $(p=0.1373)$, work experience $(p=0.2136)$, number of prescriptions involved $(p=0.2386)$. Additional information is available in supplementary table 1. 


\section{Factors associated with attitude RII score}

There was an association between aggregated attitude RII score and profession of the participant $(\mathrm{p}=$ 0.016), $71 \%$ of the students and nurses had an attitude RII score above $65 \%$, while $72 \%$ and $55 \%$ of the medical doctors and pharmacists, respectively, had an attitude RII score above $65 \%$. There was an association between aggregated attitude RII score and education level of the participant $(p=0.003), 86 \%$ of the participants educated up to $\mathrm{PhD}$ or masters' degree had an attitude RII score above $65 \%$, while $77 \%$ and $62 \%$ of the participants educated to bachelors' degree and medical sciences students, respectively, had an attitude RII score above 65\%. There was an association between aggregated attitude RII score and working institution of the participant $(p<0.001), 86 \%$ of the participants working at public institutions only had an attitude RII score above $65 \%$, while $76 \%, 75 \%$ and $80 \%$ of the participants working at both private and public institutions, as medical sciences students or private sector only, respectively, had an attitude RII score above $65 \%$. There was no association between aggregated attitude RII score and age ( $p$ $=0.200)$, gender $(p=0.344)$, work experience $(p=0.148)$, number of prescriptions involved $(p=0.2386)$. Additional information is available in supplementary table 2.

\section{Factors associated with perceptions towards pharmaceutical promotion}

There was an association between aggregated perception RII score and profession of the participant $(\mathrm{p}<$ $0.001), 100 \%$ of the medical sciences students and nurses had a perception RII score above $65 \%$, while $81 \%$ and $89 \%$ of the pharmacists and medical doctors, respectively, had a perception RII score above $65 \%$. There was an association between aggregated perception RII score and gender of the participant ( $p$ $=0.034$ ), $95 \%$ of the female participants had a perception Rll score above $89 \%$, while $94 \%$ of the male participants had a perception RII score above $65 \%$. There was an association between aggregated perception RII score and education level of the participant $(p=0.028), 100 \%$ of the participants educated up to $\mathrm{PhD}$ or are medical sciences students had a perception RII score above $65 \%$, while $92 \%$ and $85 \%$ of the participants educated to bachelors' degree and master's degree, respectively, had a perception RII score above $65 \%$. There was an association between aggregated perception RII score and working institution of the participant ( $\mathrm{p}<0.001), 100 \%$ of the medical sciences students had a perception RII score above $65 \%$, while $95 \%, 89 \%$ and $75 \%$ of the participants working at both public and private sector, public sector only, or public sector only respectively, had a perception RII score above $65 \%$. There was no association between aggregated attitude RII score and age $(p=0.305)$, work experience $(p=0.053)$, number of prescriptions involved $(p=0.090)$. Additional information is available in supplementary table 3.

\section{Relationship between knowledge, attitude and perception towards pharmaceutical promotion of the study participants}


There was a strong positive linear relationship between knowledge RII score and attitude RII score (spearman correlation coefficient $=0.5, p<0.001$ ). There was a fair positive linear relationship between knowledge RII score and perception RII score (spearman correlation coefficient $=0.3, p<0.001$ ). There was a strong positive linear relationship between perception RII score and attitude RII score (spearman correlation coefficient $=0.5, p<0.001$ ). Additional information is available in Fig. 4 .

\section{Discussion}

In this study, we estimated the HCWs' knowledge, attitude and perception levels towards regulation of pharmaceutical promotion. The relative importance index (RII) was calculated as a percentage and used as an aggregate measure for each of the knowledge, attitude and perception domains. To the best of our knowledge, this is the first report to explore HCWs knowledge, attitudes and perceptions towards regulation of pharmaceutical promotion in Zimbabwe using the RII. The RII has been used widely in the past for the purposes of overall ranking of ordinal responses [25-27]. In this study, after the calculation of the RII we used a rule of thumb that participants with a RII score above $65 \%$ are more favourable than those with a RII below or equal to $65 \%$. Results from this study estimated that $95 \%, 65 \%$ and $90 \% \mathrm{HCWs}$ have a favourable score towards the KAP RII score, respectively.

The results from this study shows that most of the HCWs in Zimbabwe have high positive knowledge with regards to the regulation of pharmaceutical promotion (i.e.95\% had RII >65\%). The result is in the range of with other studies that have estimated a knowledge score towards pharmaceutical promotion of between $50 \%$ and $90 \%$. Our further exploration of the data indicated that the HCWs' profession, gender, education level and the nature of the working institution had an association with the knowledge levels. The variables associated with knowledge score are consistent with results from previous studies that have assessed the factors associated with knowledge levels towards general medical practices [28, 29].

In addition, the results from this study shows that on average the HCWs in Zimbabwe have moderately high positive attitudes towards regulation of pharmaceutical promotion (i.e. $67 \%$ had RII > 65\%). The result is in the range of with other studies that have estimated the attitude score towards regulation of general medical practises to range between poor to moderate levels $[28,30]$. Our further exploration of the data indicated that the HCWs' profession, education level, the nature of the working institution, and the number of prescriptions involved per week had an association with the attitude levels towards regulation of pharmaceutical promotion. Also, similar to knowledge levels, the variables associated with attitude levels are consistent with results from previous studies that have assessed factors associated with the attitude levels towards general medical practices [31, 32].

Also, the results obtained from this study shows that most of the HCWs in Zimbabwe have high positive perceptions towards regulation of pharmaceutical promotion (i.e. $90 \%$ had RII $>65 \%$ ). The result is in the range of with other studies that have estimated the perception scores towards general medical practises to be high $[28,30]$. Our further exploration of the data indicated that the healthcare practitioners' profession, gender, education level, and the nature of the working institution had an association with the 
perception towards regulation of pharmaceutical regulation. Also, similar to knowledge and attitude levels, the variables associated with perception levels are consistent with results from previous that have assessed factors associated with the attitude levels towards general medical practices [31, 32].

A major limitation to this study is that we the survey response did not reach the minimum 423 subjects required based on the sample size determination procedure due to the time available as stipulated by the university requirements since the research was performed as part of the requirements for fulfilment of a postgraduate degree, hence the marginal effect of the results estimates could be compromised. Additionally, due to the fact that the method of data collection was based on both interviewer administered and self-administered web-based platform, the quality of responses from the web-based platform could have brought additional bias in the event that the survey participants fail to understand some of the questionnaire variables.

\section{Conclusion}

In conclusion, the findings of this study highlighted that HCWs have high positive KAP towards regulation of pharmaceutical promotion, though the attitudes levels was a bit lower when compared to other domains. Policy makers and regulators still have to be concerned about the impact of pharmaceutical promotion and advertisement on HCWs' behaviours. Continued enforcement of regulations and laws that protect the public from the profit oriented organizations seeking to promote their pharmaceutical products is strongly recommended. Further education and training is recommended to HCWs in order to improve their attitude towards the regulation of pharmaceutical promotion. Future studies should incorporate the views of the policy makers, distributors, patients and other stakeholders with regards to regulation of pharmaceutical promotion. Additionally a review and evaluation of statutory instruments that regulate pharmaceutical promotion in Zimbabwe and other regional countries is recommended.

\section{Declarations}

\section{Ethics approval and consent to participate}

The study obtained approval to carry the study from the Joint Research Ethics Committee (JREC JREC/266/2021). Each participant provided consent to participate in the study. The study was perfomed while observed good clinical practices and in accordance with the Helsinki declaration.

\section{Consent for publication}

$N / A$

\section{Availability of data and material}

The study is yet to publish the data to the public, however the data can be available upon request and approval from the corresponding author. 


\section{Competing interests}

The authors declare that there is no conflict of interest.

\section{Funding}

The study was funded by the corresponding author

\section{Authors' Contributions}

T.C.S and T.M were involved in conceptual development. T.C.S, B.N and T.M were involved in full proposal development. T.C.S and B.N were involved in data collection, management and analysis. T.C.S, B.N and T.M were involved in interpretation and discussion of results. All the authors have read and approved the manuscript.

\section{Acknowledgements}

The authors would like to acknowledge the study participants for affording their time in participating in the survey.

\section{References}

1. Ms W, Jr H. An innovative approach to educating medical students about pharmaceutical promotion [Internet]. Acad. Med. J. Assoc. Am. Med. Coll. Acad Med; 2001 [cited 2021 Mar 6]. Available from: https://pubmed.ncbi.nlm.nih.gov/11739058/

2. Ashker S, Burkiewicz JS. Pharmacy residents' attitudes toward pharmaceutical industry promotion. Am J Health-Syst Pharm AJHP Off J Am Soc Health-Syst Pharm. 2007; 64(16):1724-1731.

3. Crigger NJ. Pharmaceutical promotions and conflict of interest in nurse practitioner's decision making: The undiscovered country. J Am Acad Nurse Pract. 2005; 17(6):207-212.

4. Semin S, Guidal D, Ozcakar N, Mevsim V. What patients think about promotional activities of pharmaceutical companies in Turkey [Internet]. Pharm. World Sci. PWS. Pharm World Sci; 2006 [cited 2021 Mar 6]. Available from: https://pubmed.ncbi.nlm.nih.gov/17066242/

5. Windmeijer F, Laat E de, Douven R, Mot E. Pharmaceutical promotion and GP prescription behaviour. Health Econ. 2006; 15(1):5-18.

6. Moynihan R. Who pays for the pizza? Redefining the relationships between doctors and drug companies. 1: entanglement. BMJ. 2003; 326(7400):1189-1192.

7. Lexchin J. Interactions between physicians and the pharmaceutical industry: what does the literature say? CMAJ Can Med Assoc J. 1993; 149(10):1401-1407.

8. Wazana A. Physicians and the pharmaceutical industry: is a gift ever just a gift? JAMA. 2000; 283(3):373-380. 
9. Naik RK, Borrego ME, Gupchup GV, Dodd M, Sather MR. Pharmacy students' knowledge, attitudes, and evaluation of direct-to-consumer advertising. Am J Pharm Educ. 2007; 71(5):86.

10. Manasse HR, Speedie MK. Pharmacists, pharmaceuticals, and policy issues shaping the work force in pharmacy. Am J Pharm Educ. 2007; 71(5):82.

11. Banks D. Pharmacists, pharmaceutical manufacturers, and conflicts of interest. Am J Health-Syst Pharm AJHP Off J Am Soc Health-Syst Pharm. 2005; 62(17):1827-1832.

12. Al-Haddad MS, Hamam F, Al-Shakhshir SM. General public knowledge, perceptions and practice towards pharmaceutical drug advertisements in the Western region of KSA. Saudi Pharm J SPJ Off Publ Saudi Pharm Soc. 2014; 22(2):119-126.

13. Datta A, Dave D. Effects of Physician-directed Pharmaceutical Promotion on Prescription Behaviors: Longitudinal Evidence. Health Econ. 2017; 26(4):450-468.

14. Fickweiler F, Fickweiler W, Urbach E. Interactions between physicians and the pharmaceutical industry generally and sales representatives specifically and their association with physicians' attitudes and prescribing habits: a systematic review. BMJ Open. 2017; 7(9):e016408.

15. Gupta SK, Nayak RP, Sivaranjani R. A study on the interactions of doctors with medical representatives of pharmaceutical companies in a Tertiary Care Teaching Hospital of South India. J Pharm Bioallied Sci. 2016; 8(1):47-51.

16. Kyrgyzstan_Law_non-commercial_organisations_2013_en.pdf [Internet]. [cited 2021 Mar 6]. Available from: https://www.legislationline.org/download/id/7579/file/Kyrgyzstan_Law_noncommercial_organisations_2013_en.pdf

17. Yousif M. Influence of pharmaceutical industry's promotion on the doctors' prescribing patterns in Sudan. J Med Use Dev Ctries 2009133 - 13. 2009;.

18. Khazzaka M. Pharmaceutical marketing strategies' influence on physicians' prescribing pattern in Lebanon: ethics, gifts, and samples. BMC Health Serv Res. 2019; 19(1):80.

19. Alosaimi FD, Al Kaabba A, Qadi M, et al. Physicians' attitudes towards interaction with the pharmaceutical industry. East Mediterr Health J Rev Sante Mediterr Orient Al-Majallah Al-Sihhiyah LiSharq Al-Mutawassit. 2015; 20(12):812-819.

20. Jamshed SQ, Ibrahim MIM, Hassali MAA, et al. Perception and attitude of general practitioners regarding generic medicines in Karachi, Pakistan: A questionnaire based study. South Med Rev. 2012; $5(1): 22-30$.

21. Zahrani HSA. The impact of pharmaceutical promotions on primary health care physician\'s prescribing behaviour in KAMC in central region -. Int J Med Sci Public Health. MedScience (India); $2014 ; 3(3): 358-361$.

22. European Symposium on Clinical Pharmacological Evaluation in Drug Control, World Health Organization, Regional Office for Europe, European Symposium on Clinical Pharmacological Evaluation in Drug Control, editors. Clinical pharmacological evaluation in drug control: report on the eighteenth European Symposium, Bad Neuenahr, 10-13 December 1991. Copenhagen: Regional Office for Europe, World Health Organization; 1993. 
23. Brezis M, Wiist WH. Vulnerability of health to market forces. Med Care. 2011; 49(3):232-239.

24. Promotional practices in LMICs of Medicines by Pharmaceuticals [Internet]. Health Action Int. [cited 2021 Mar 6]. Available from: https://haiweb.org/encyclopaedia/promotional-practices-in-Imics/

25. Azman NS, Ramli MZ, Razman R, Zawawi MH, Ismail IN, Isa MR. Relative importance index (RII) in ranking of quality factors on industrialised building system (IBS) projects in Malaysia. AIP Conf Proc. American Institute of Physics; 2019; 2129(1):020029.

26. Relative Importance Index (RII) | Scientific.Net [Internet]. [cited 2021 Jul 14]. Available from: https://www.scientific.net/paper-keyword/relative-importance-index-rii

27. The relative importance index RII was calculated using the following formula | Course Hero [Internet]. [cited 2021 Jul 14]. Available from: https://www.coursehero.com/file/p3bvhdl/The-relativeimportance-index-RIl-was-calculated-using-the-following-formula/

28. Wake AD. Knowledge, Attitude, Practice, and Associated Factors Regarding the Novel Coronavirus Disease 2019 (COVID-19) Pandemic. Infect Drug Resist. 2020; 13:3817-3832.

29. Churko C, Asnakew Asfaw M, Tunje A, Girma E, Zerdo Z. Knowledge, attitude, practice and associated factors of health professionals towards podoconiosis in Gamo zone, Ethiopia, 2019. J Foot Ankle Res. 2021; 14(1):31.

30. Bitew G, Sharew M, Belsti Y. Factors associated with knowledge, attitude, and practice of COVID-19 among health care professional's working in South Wollo Zone Hospitals, Northeast Ethiopia. SAGE Open Med. SAGE Publications Ltd; 2021; 9:20503121211025148.

31. Ahmad A, Munn Sann L, Abdul Rahman H. Factors associated with knowledge, attitude and practice related to hepatitis $B$ and $C$ among international students of Universiti Putra Malaysia. BMC Public Health. 2016; 16(1):611.

32. Wen X, Wang F, Li X, Gu H. Study on the Knowledge, Attitude, and Practice (KAP) of Nursing Staff and Influencing Factors on COVID-19. Front Public Health [Internet]. Frontiers; 2021 [cited 2021 Jul 15]; 0. Available from: https://www.frontiersin.org/articles/10.3389/fpubh.2020.560606/full

\section{Figures}




\section{$=$ Strongly agree $=$ Agree $=$ Neutral $=$ Disagree $\quad$ Strongly disagree}

12.Advertisements to the general public should help people to make rational decisions on the use of medicines?

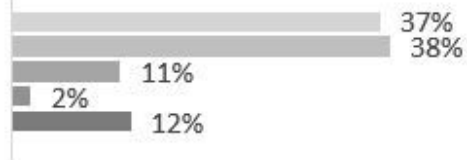

11.Information on adverse reactions, precautions, contraindications and wamings, food and medicine interactions should be available before...

10. Advertisements should claim that a medicine can cure, prevent, or relieve an ailment only if this can be substantiated?

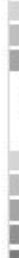

9.The pharmacist is not allowed to dispense a different brand of the drug without refering back to the prescriber?

8.It should not be assumed that a new product efficacy, quality and safety are similar to the already available medicines?

7.Advertisements should not be directed at children?

6.Changes to the approved advertising material should also go through the approval process?

5.A person is not permitted to advertise medicines in connection with any bonus or discount offered?

4.The advertisement of any unregistered medicine is not permitted?

3.Medicines in Zimbabwe cannot be advertised without the approval of the Medicines Control Authority in writing?

2.Are you aware of the guidelines for advertising and promotion of medicines in Zimbabwe?

1.The term pharmaceutical promotion refers to marketing of a drug product?

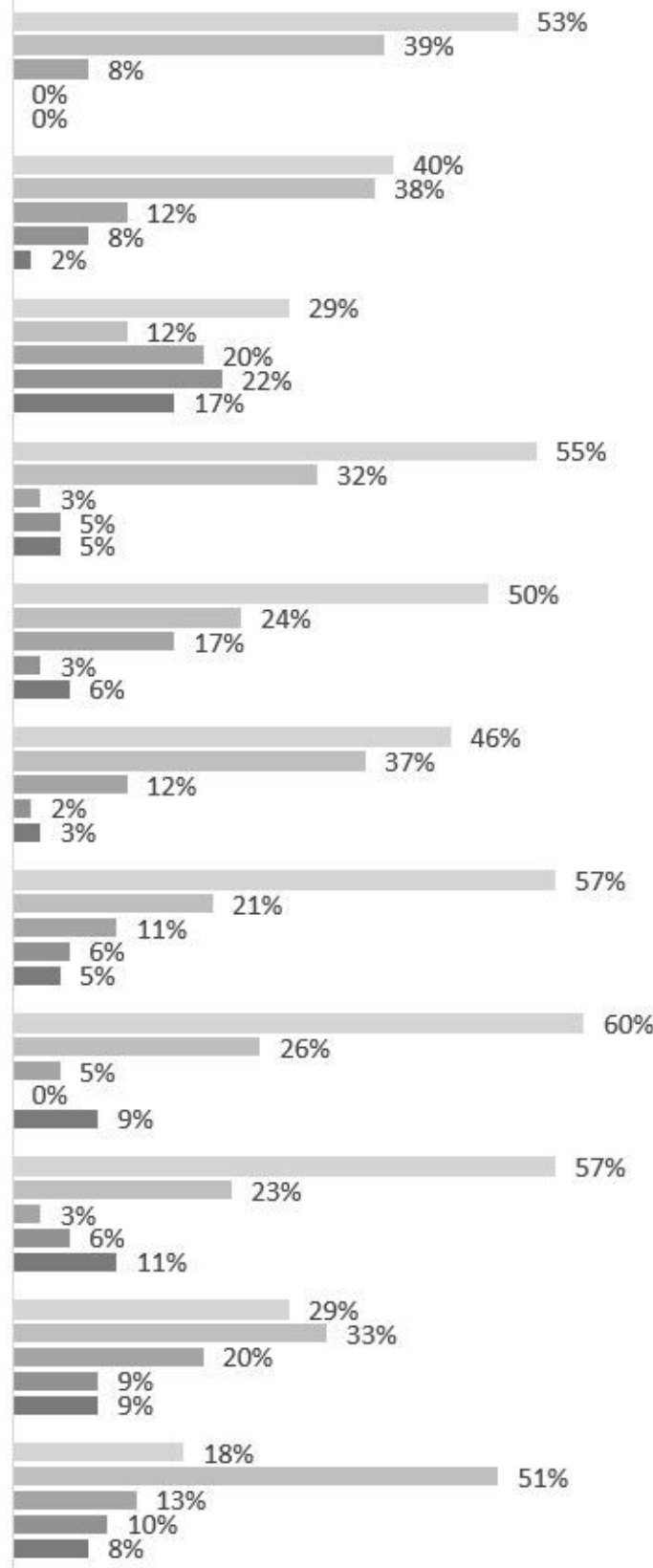

\section{Figure 1}

\section{Knowledge levels towards pharmaceutical promotion}




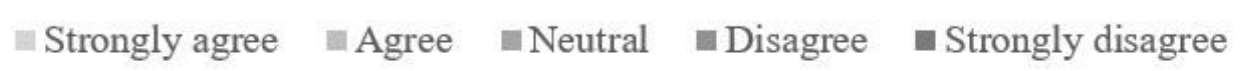

9.Regulation should avoid the provision of promotional aids by pharmaceutical industries?

8.Regulation should demand acceptable venues and locations for meetings and continuing medical education?

7.Regulation should avoid companies from sponsorship or support for healthcare professionals' attendance at meetings and continuing medical education?

6.Regulation has improved the standards for interactions between companies and healthcare professionals?

5.Regulation improves the ethical and professional behavior, putting patients first and compliance in the presence of medicines advertisement?

4.Regulation should not allow health care workers in Zimbabwe the right for medicine substitution?

3.Regulation reserve rights for patients to be given enough explanations about the reasons for choice of medicines for them?

2.Regulation manages to avoid the pharmaceutical industry from influencing healthcare workers on decisions to prescribe and dispense?

1.I support initiatives towards regulation of medicines advertisement.

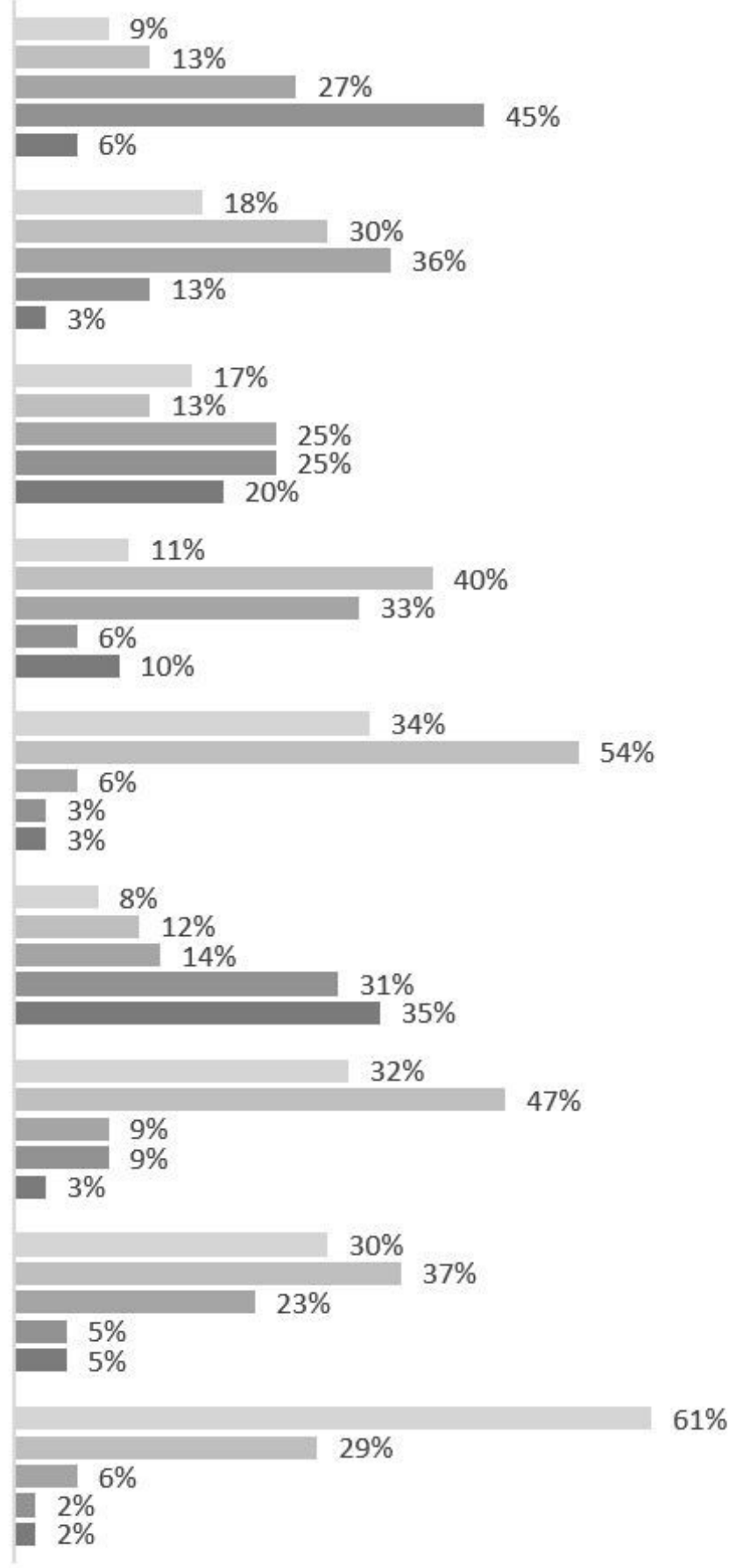

\section{Figure 2}

Attitude levels towards pharmaceutical promotion 
- Strongly agree $\square$ Agree $\quad$ Neutral $\quad$ Disagree $\quad$ Strongly disagree

7.Poor regulation of pharmaceutical promotion allows pharmacists to perform medicine substitution without consulting the prescribing physician?

6.Poor regulation of pharmaceutical promotion can influence unjustified medicines regimen switching?

5.Poor regulation of pharmaceutical promotion may lead to over-expenditure on medicines?

4.Poor regulation of pharmaceutical promotion may lead to sub-optimal dispensing?

3.Poor regulation of pharmaceutical promotion may lead to sub-optimal prescription?

2.Health authorities in Zimbabwe should implement policies such that bioequivalence data are mandatory before a product is marketed?

1.The intensity of promotional activities by medical representatives should be regulated?

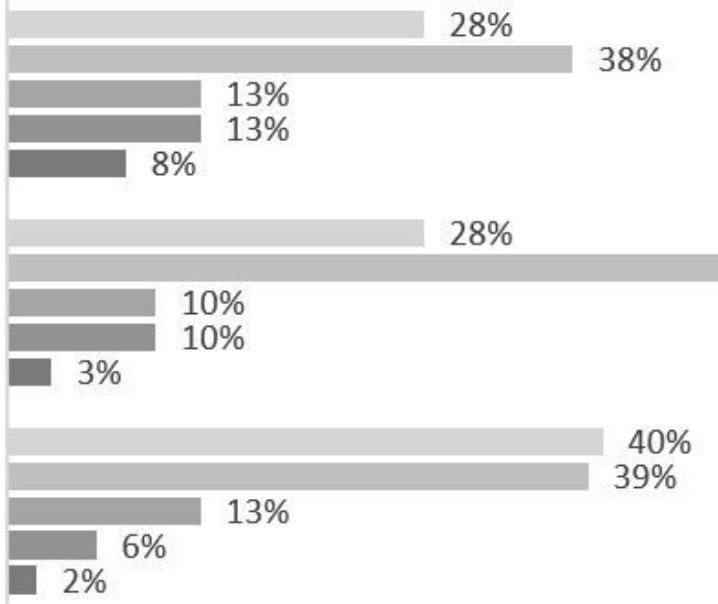

$35 \%$
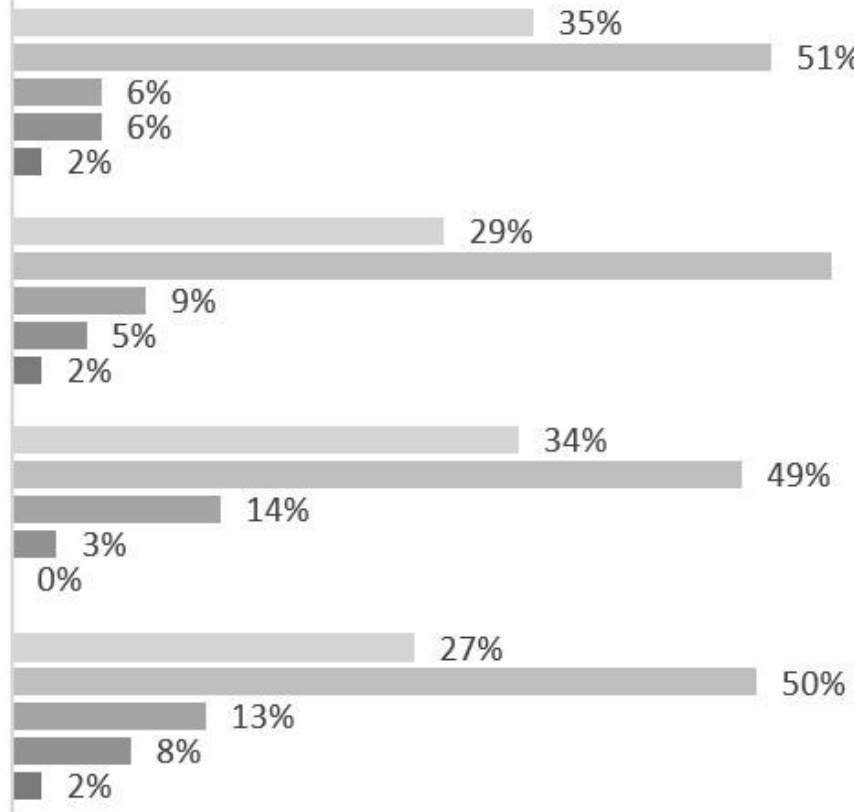

\section{Figure 3}

Perception levels towards pharmaceutical promotion 


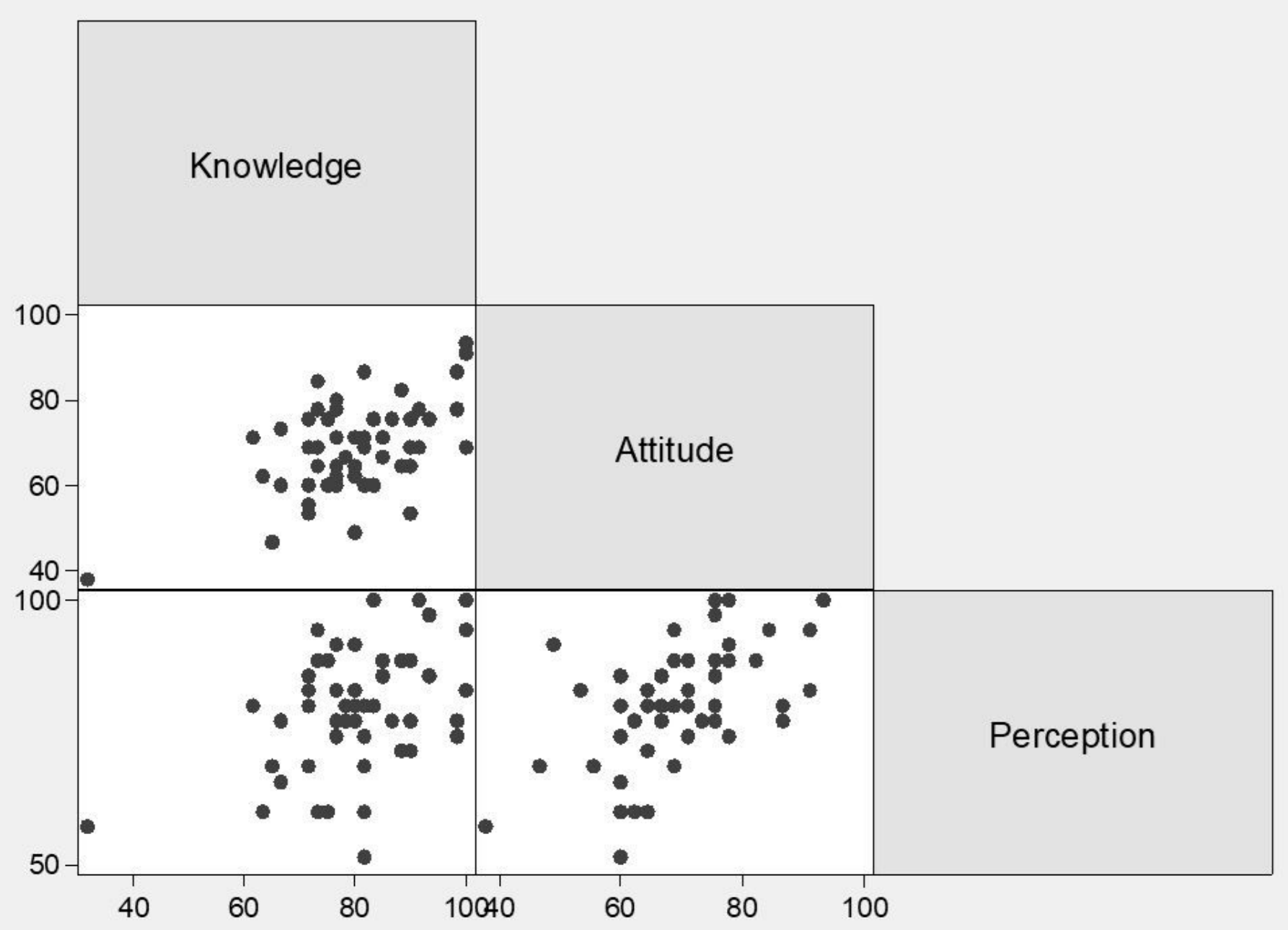

Figure 4

Scatter matrix to determine linear relationship between knowledge, attitude and perception RII scores towards pharmaceutical promotion of the study participants

\section{Supplementary Files}

This is a list of supplementary files associated with this preprint. Click to download.

- semutables.docx 